\title{
Cancer stem cells and nanotechnological approaches for eradication
}

\author{
Gholam Basati ${ }^{1}$, Mojtaba Khaksarian², Saber Abbaszadeh ${ }^{3}$, Hamed Esmaeil Lashgarian ${ }^{4}$, \\ Abdolrazagh Marzban ${ }^{5}$
}

${ }^{1}$ Clinical Microbiology Research Center, Ilam University of Medical Sciences, Ilam, Iran; ${ }^{2}$ Razi Herbal Medicine Research Center \& Department of Physiology, ${ }^{3}$ Student Research Committee, ${ }^{4}$ Department of Biotechnology, School of Medicine, Hepatitis Research Center, ${ }^{5}$ Razi Herbal Medicines Research Center, Lorestan University of Medical Sciences, Khorramabad, Iran

Contributions: (I) Conception and design: G Basati; (II) Administrative support: None; (III) Provision of study materials or patients: None; (IV) Collection and assembly of data: M Khaksarian, S Abbaszadeh; (V) Data analysis and interpretation: M Khaksarian, S Abbaszadeh; (VI) Manuscript writing: All authors; (VII) Final approval of manuscript: All authors.

Correspondence to: Abdolrazagh Marzban. Razi Herbal Medicines Research Center, Lorestan University of Medical Sciences, Khorramabad, Iran. Email: marzban86@gmail.com.

\begin{abstract}
Cancer stem cells (CSCs) are currently known as the main cause of tumor recurrence. After chemotherapy is completed, CSCs proliferate and then differentiate to generate new tumor tissues. Similar to normal stem cells, this non-uniformly distributed cell population in the tumor tissue has selfrenewal capacity and is responsible for survival of the tumor and difference in its genetic and metabolic characteristics. Followed by gene instability in CSCs, new phenotypic markers are aberrantly expressed in CSCs subpopulation. Hence, some of the surface markers and metabolic pathways that are upregulated in CSCs may be applied as specific targets for development of diagnostic and therapeutic approaches. In this review article, the distinctive properties of CSCs including signal pathways implicated in self-renewal and surface markers were discussed. Moreover, targeting CSCs based on their specific properties using nanodrugs was reviewed.
\end{abstract}

Keywords: Cancer stem cells (CSCs); self-renewal; nano-formulations; surface markers

Received: 14 August 2019; Accepted: 08 October 2019; Published: 28 November 2019.

doi: $10.21037 /$ sci.2019.10.07

View this article at: http://dx.doi.org/10.21037/sci.2019.10.07

\section{Introduction}

After the theory of the presence of stem cells in the population of tumor cells was introduced by Bonnet et al. (1), several studies were conducted on how these cells were generated $(2,3)$. In this regard, researchers sought to characterize cancer stem cells (CSCs) from cancer cell populations. Although these efforts gained relative success in the early stages of cancer, it failed to isolate a homogeneous population of CSCs in advanced stages $(4,5)$ (Figure 1).

Subsequently, while observing a heterogeneous subpopulation in leukemia, researchers identified a small, clonogenic cell population whose characteristics were similar to those of blood stem cells. Given the clonogenic and heterogeneous nature of tumors, they suggested that there was a rare cell population in cancers that acted like stem cells and was responsible for tumor growth and metastasis. In fact, the results showed that CSCs could be derived from normal stem cells or from committed progenitor cells that had obtained self-renewal capacity $(6,7)$. These cells are highly similar to normal stem cells with respect to self-renewal and metabolic characteristics (2). However, there are certain differences between CSCs and normal stem cells. These lead to different types of cancer cells with varying metabolic activity, and in different stages of tumor evolution, guarantee tumor survival under severe conditions, even under the influence of strong 


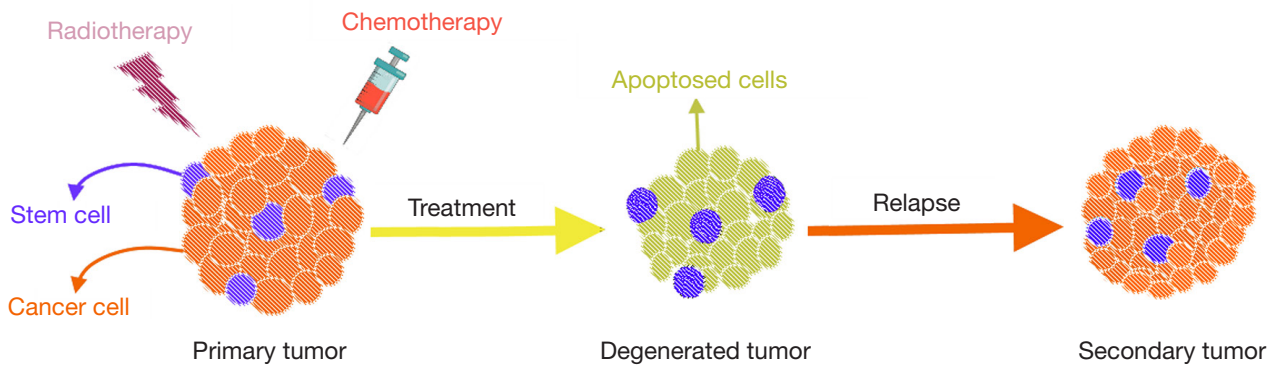

Figure 1 A schematic of the classical therapeutic approaches against a tumor growth. In the heterogeneous differentiation model, CSCs having potential of resistance to radiation and chemotherapy can cause recurrence of the tumor. CSCs, cancer stem cells.

chemotherapy drugs (8). Many studies have shown that CSCs are generated from genetic changes occurring in a cell population, and following the formation of these cells, the gene expression profile in cancer cells changes (9). With the changes in the genetic or epigenetic profiles of CSCs, new distinctions were emerged in the molecular metabolism, surface markers profile and signaling pathways, which were shown to be involved in self-renewal, drug resistance, proliferation and differentiation $(10,11)$.

Currently, extremely few drugs with definitive outcomes have been developed with high efficacy against CSCs, such as salinomycin, cisplatin, doxorubicin, vincristine, paclitaxel and their synthetic derivatives, which have a highly disruptive impact on various cancer cells (12-17). Because of the non-specific toxicity of these drugs in all cells, only targeted nano-formulation drugs have the potential to target CSCs and break drug-resistance in cancer cells. Many nano-formulations have been developed as combinations of chemical and biological derivatives such as plant bioactive products and microbial secondary metabolites that might play a dual role in cancer treatment. For example, curcumin and its analogues, which are used in clinical cancer studies due to their anticancer and prophylactic effects, are able to decrease the side effects of chemotherapy and radiotherapy on normal tissues $(12,18,19)$.

Another challenge lies in drug delivery to brain tumors that are strictly protected by brain-blood barrier (BBB). Actually, the BBB has been constituted of highly regulated structure that does not allow drugs present in blood circulation to be enter the brain tissue. Thus, many efforts have been conducted to develop effective drug delivery systems that are able to across the BBB. In this regard, to efficiently deliver therapeutic molecules to the tumor location in the brain, various nanopharmaceutical systems have been formulated such as lipid-based nanoparticles, hydrophobic nanocarriers, functionalized compatible polymeric nanoparticles etc (20-25).

Developing nanotechnology-based therapeutic systems have improved many of the known limitations of anticancer drugs, such as low water solubility, stability and non-specific toxicity $(19,26)$. Additionally, these nanodrug formulations have indicated high potential of controlling the release of anti-tumor drugs and protecting them from rapid metabolization and elimination. The controlled release of drugs, rational design of specific targeting of cancer cells and accurate diagnostic techniques of these cells can help to treat cancer $(27,28)$. In this respect, by detecting specific properties of CSCs, various formulations were developed via designing effective nanodrugs, which specifically target CSCs in tumor tissues $(29,30)$.

This review paper discussed key pathways involved in the development and survival of tumor cells that may be appropriate targets for the design of antitumor drugs based on nanoscale formulations.

\section{Targeting active genes in CSCs}

New approaches to target genes that implicate in drug resistance, self-renewal and in CSCs are developed based on gene silencing by specific RNA inhibitors such as siRNAs, miRNAs and LncRNAs (31-35). For example, $M D R 1$ gene silencing in drug-resistant tumors can reduce the expression of $\mathrm{P}$-gp transporters and increase the efficacy of chemotherapy (36). The low sustainability and accumulation of these therapeutic molecules have led to many efforts in recent years to design nanodrug delivery systems. For example, in a study of siRNA against Signal transducers and activators of transcription (STAT3) in PEI-PLGA nanoparticles as a part of a combination treatment, paclitaxel-siRNA was used for A549/T12 
(paclitaxel-resistant cell line) (37). In another study, a lipid based nanocarrier was used to effectively deliver siRNA to lung cancer cells, A549 (38). In one other study, two siRNA including STAT3 and GRP78 were delivered using polycation-functionalized nanoporous silicon microparticles, resulting in suppressed STAT3 expression in MDA-MB-231 breast cancer cells and reduced self-renewal capacity of CSCs in tumor tissues (39).

\section{CSCs targeting via specific surface markers}

By characterizing the metabolic pathway, genetic profile, resistance pattern and microenvironmental condition in CSCs, many efforts were conducted to target these specialized factors via nanodrug delivery (40). Many surface biomarkers, specific to CSCs, such as $\mathrm{Cx} 43$, CD44, CD133 and $\mathrm{CD} 34^{+}$can be used as targets for cancer treatment (38,41-43). Therefore, one of the most effective strategies for targeting various tumor cells is to link nano-formulations of drugs to specific antibodies against tumor markers. To treat pancreatic and breast cancer, efficient nano-magnetic particles in combination with gentamicin and in conjugation with anti-CD44 were applied for targeting CD44 marker in the surface of adult cancer cells (ACCs) and CSCs. This nano-formulation successfully eliminated complete tumor cells, especially CSCs (44). In addition, an efficient formulation of nano-curcumin was found to significantly inhibit anchorage-independent clonogenic growth and also reduce the stem cell population CD133 in medulloblastoma and glioblastoma (45). In another study, vincristine/silver nanoparticles conjugated to an anti-ABCG1 antibody was exploited for targeting myeloma cancer cells, which resulted in a synergetic cytotoxic effect on tumor cells in mice (46). Yang et al. (2014) applied an efficient formulation as a combination of $\gamma$-Fe2O3 nanoparticles and paclitaxel that was conjugated with anti-ABCG1 for inducing apoptosis gene expression and downregulation of the NF- $\mathrm{KB}$ gene in multiple myeloma CSCs (47).

Thus, with the advent of CSCs manifesting unique properties such as self-renewal ability and overexpression of surface markers, these specific surface markers are found to be ideal targets for designing novel drug formulations that are able to select and eliminate CSCs subpopulation $(28,48,49)$.

These studies have led to the identification of a wide range of markers on the surface of CSCs. Some of the most specific markers for CSCs in human and animal cells are introduced in Table 1.

\section{Signaling pathways for drug targeting}

Molecular signaling pathways that control the homeostasis of normal stem cells are tightly regulated. These regulations are disrupted by changes occurring in many cancerous cells. Numerous studies have demonstrated that abnormalities in the cell regulatory system play a critical role in the promotion of self-renewal, cell survival, proliferation and differentiation of CSCs. During the tumor progression, the ability to self-renew CSCs may be increased, weakened or even missed through subsequent mutations $(55,87,88)$. In fact, these signaling pathways may activate some genes involved in the formation of CSCs and relapse of cancer after chemotherapy. The signal network involved in the development of cancer covers many pathways, which express numerous cell surface markers, i.e., cell membrane proteins (89). These tumor markers are useful indicators for the design of diagnostic tests and also important targets for targeting antitumor medications drugs.

As CSCs can survive radiation and chemotherapy, specific identification of all tumorigenic components can represent an effective therapeutic strategy for targeting tumor integrity. In this regard, many efforts have been adopted to identify mechanisms of signaling involved in self-renewal, differentiation and proliferation. Table 2 shows some signaling pathways including Hedgehog, Notch, Wnt/ $\beta$-catenin, BmiI1, PTEN and TGF- $\beta$, which might be responsible for proliferation, proliferation, malignancy, drug resistance and tumor recurrence.

These signal pathways are currently attractive targets for drug delivery to tumor tissues, especially CSCs. Many efforts are made to disrupt signals associated to tumor progression as well as to self-renewal and differentiation of CSCs, which may lead to complete removal of a tumor.

One of the most important signal pathways is the Wnt/ $\beta$-catenin pathway that is known as an essential activator of several transcription factors responsible for survival, self-renewal and differentiation properties of normal stem cells. It also appears that the $\mathrm{Wnt} / \beta$-catenin signaling pathway can play a pivotal role in the formation of CSCs and establishment of their self-renewal capacity (90-92). In this regard, the role of the Wnt signaling pathway has been significantly confirmed in recurrence of breast cancer and myeloid leukemia as well as in progression of liver fibrosis alteration (93-96). In this context, Mao et al. (2014) showed that suppression of the Wnt signaling pathway led to the inhibition of the proliferation of CD44+Oct4-CSC subclone (97). 
Table 1 Main specific markers that were found to be present over the various CSCs

\begin{tabular}{|c|c|c|}
\hline Types of CSC origin & Specific marker & Reference \\
\hline Colorectal cancer & 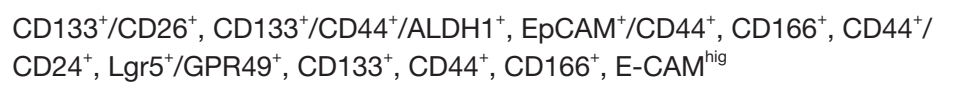 & $(58-61)$ \\
\hline Chronic myeloid leukemia & $\mathrm{CD}^{4} 4^{+}, \mathrm{CD}_{3} 8^{-}, \mathrm{CD}_{123^{+}}, \mathrm{CD}_{26}^{+}$ & $(65,66)$ \\
\hline Blast-crisis CML & $\mathrm{CD}^{2} 4^{+}, \mathrm{CD} 8^{+}, \mathrm{CD} 123^{+}$ & (63) \\
\hline Bone sarcomas & Stro- $1^{+}, \mathrm{CD} 105^{+}, \mathrm{CD} 44^{+}, \mathrm{NKX} 2$ & $(67,68)$ \\
\hline Head and neck squamous cell carcinoma & $\mathrm{CD}_{4} 4^{+}, \mathrm{ALDH}^{+}, \mathrm{CD} 44 / \mathrm{CD} 133$ & $(74-76)$ \\
\hline Gastric cancer & $\mathrm{CD}_{133^{+}}, \mathrm{CD}_{4} 4^{+}, \mathrm{Lgr} 5, \mathrm{CD}^{+}, \mathrm{CD}^{-} 1^{-}$ & $(40,77,78)$ \\
\hline Melanoma & $\mathrm{CD}_{20}{ }^{+}, \mathrm{CD}_{133^{+}}, \mathrm{ABCB}^{+}$, nestin, $\mathrm{CD} 271^{+}$ & $(48,79)$ \\
\hline Hepatocellular carcinoma & $\mathrm{CD} 133^{+}, \mathrm{CD} 0^{+}, \mathrm{CD} 0^{+} / \mathrm{CD} 45, \mathrm{EpCAM}^{+}, \mathrm{CD} 3^{+}, \mathrm{CD} 133^{+} / \mathrm{CD} 4 \mathrm{f}^{+}, \mathrm{CD} 44^{+}$ & $(80-82)$ \\
\hline Ovarian cancer & $\mathrm{CD}_{4} 4^{+}, \mathrm{MyD} 8^{+}, \mathrm{CD} 133^{+}$ & $(83,84)$ \\
\hline Lung cancer & $\mathrm{ALDH}^{+}$, Sca1CD45-PecamCD34, CD133 ${ }^{+}, \mathrm{CD}^{+} 0^{+}$ & $(85,86)$ \\
\hline
\end{tabular}

CSCs, cancer stem cells; CML, chronic myeloid leukemia.

Table 2 Signaling pathways involved in the self-renewal process of some CSCs

\begin{tabular}{|c|c|c|}
\hline Tumor type & Signal pathway & Reference \\
\hline Glioblastoma & Hedgehog, Notch, PI3K/Akt/PTEN/mTOR, cAMP-Epac, NF-кB, Jak/STAT & $(29,76-78)$ \\
\hline Leukemia & Wnt/ß-catenin, Hedgehog, PI3K/Akt/PTEN/mTOR & $(79)$ \\
\hline Gastrointestinal & $\mathrm{NF}-\kappa \mathrm{B}, \mathrm{Wnt} / \beta$-catenin & $(80)$ \\
\hline Prostate & Jak/STAT, PI3K/Akt/PTEN/mTOR, & $(40,83)$ \\
\hline Lung & $\mathrm{PI3K} / \mathrm{Akt} / \mathrm{PTEN} / \mathrm{mTOR}$, Wnt/ß-catenin & $(84,85)$ \\
\hline Osteosarcoma & Notch, Wnt/ $\beta$-catenin, PI3K/Akt/PTEN/mTOR, RANKL/RANK & $(86,87)$ \\
\hline
\end{tabular}

Another important signal pathway is Hedgehog that regulates several genes during the development of embryogenesis in normal cells. Evidence shows that the abnormal activation of Hedgehog pathways promotes tumor cells to produce CSCs clone and enhance chemoresistance and survival via induction of self-renewal capacity in CSCs (98). Since the crucial role of Hedgehog pathways has been well documented by several studies, nanodrugs targeting the regulatory molecules of Hedgehog pathways are good candidates for cancer therapy. In this respect, several nano-based drug formulations including nanopolymers containing anticancer drugs, siRNA, miRNA and drug-gene combination systems have been designed that target various molecules of Hedgehog 
pathways in CSCs and/or ACCs (99-102).

The Jak/STAT pathway is a modulatory pathway that induces multiple signal cascades involved in self-renewal, proliferation and differentiation of CSCs. To inhibit the abnormal expression of Jak/STAT mediators, many efforts have been made through specific targeting by using nanosize molecules carrying different anticancer drugs or delivering some types of genes for suppressing oncogenes and/or activating apoptosis genes $(34,37)$.

The Notch pathway is composed of five ligands (DLL1-4 and JAG1-2) and four receptors (Notch1-4) making up an integral transmembrane protein. Activation of the Notch pathway occurs through binding the related ligands to receptors on the surface of adjacent cells $(48,61,103)$. This pathway contributes to development of embryonic stem cells and guarantees CSCs survival in cancer cells when Notch signaling is enriched by aberrant upregulations of related genes (80). On the other hand, with inhibition of the Notch pathway, self-renewal, clonogenic potential, chemoresistance and radioresistance ability significantly decrease (104).

The PI3K/Akt/PTEN/mTOR network pathway is evolutionarily conserved molecular network that has shown to possess a strategic role for controlling proliferation and differentiation. Recent studies have demonstrated the role of the PI3K/Akt/mTOR signaling pathway in tumor metastasis, propagation, and angiogenesis. Activation of PI3 K increases the chemoresistance capacity of cancer cells occurring by overexpression of multidrug resistance protein 1 (MDRP-1) (32). PTEN acts as a negative regulator in PI3K/Akt signaling that can inhibit metastasis and autophagy by inhibiting the Akt/mTOR pathway. Additionally, PTEN signaling effectively contracts the PI3K activity leading to inactivation of self-renewal capacity as well as radio and chemoresistance functions in CSCs (99). Therefore, the PI3K/Akt/PTEN/mTOR network pathway appears to be an ideal target for cancer therapy using nanobased drug formulations $(41,99,105)$.

Another important pathway contributing to development of CSCs properties including self-renewal, proliferation and differentiation properties is NF- $\mathrm{NB}$ complex that consists of five proteins with dimmers active feature. This complex is normally inhibited in cells by an inhibitor called I $\kappa \mathrm{B}$ protein (61). Activation of NF- $\kappa \mathrm{B}$ takes place by binding ligands such as TNF- $\alpha$, IL- $1 \beta$ and bacterial cell ghost, resulting in ubiquitination/degradation

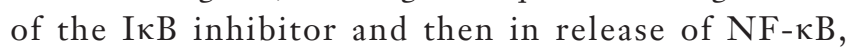
migration to nucleus and activation of gene transcription.
Mutation in NF- $\kappa \mathrm{B}$ has been shown to cause malignancies in several cancer cells such as gastrointestinal, thoracic, and head and neck malignancies as well as breast cancer and other tumors (106).

As can be reviewed in Table 1, signaling pathways contribute to acquisition of CSCs properties and consequently enhance survival with self-renewal and promote recurrence of the tumor after a conventional therapeutic regime such as radiation and chemotherapy. Currently, many researchers have focused on designing various nano-vehicles such as nanoparticles, nanocapsules and nanoemulsions, nanobiopolymers, nanolipid particles, graphene-based nanocomposites, etc. These formulations have been applied for loading various anticancer drugs, herbal drugs, and chemical and bacterial toxins for targeting tumor cells (107-110). Additionally, nano-vehicles have been documented to be efficient carriers for gene delivery into tumor cells to induce apoptosis pathways and inactivate resistance genes. Table 3 presents some nano-vehicles applied for targeting tumor tissues, which are capable of eliminating CSCs.

\section{Removal of CSC niche}

Various abnormalities in the tumor tissues have offered some advantages such as radiation and drug resistance, tumor growth promotion, invasion and malignancy for cancer cells. Tumor microenvironment is highly abnormal region that caused by metabolic changes such as acidic $\mathrm{pH}$, hypoxic condition, redox potential change, up-regulation of secreted proteins and hyperthermia. This unique condition can be applied to design drug formulations based on nanotechnology, which specifically target tumor cells (121-123).

Several studies are being conducted to develop various physico-chemical methods for destruction of cancer cells and their environments. In some of them, the goal is to release nanoparticles containing the drug, which is followed by photodynamic therapy with radiation (114). In various studies, gold nanoparticles of $10-20 \mathrm{~nm}$ in diameter modified with specific antibodies against EGFR1 or MUC1 have been used (124). Radiation to gold nanoparticles causes a localized increase in temperature around the tumor, leading to rapid destruction of cancer cells, in which these nanoparticles accumulate (125). Wolf et al. (2015) have recently used goserelin-conjugated gold nanorods to increase radiosensitization for effective internalization of gold nanoparticles to prostate cancer cells through 
Table 3 Nano-formulations of anticancer drugs for targeting different cancers.

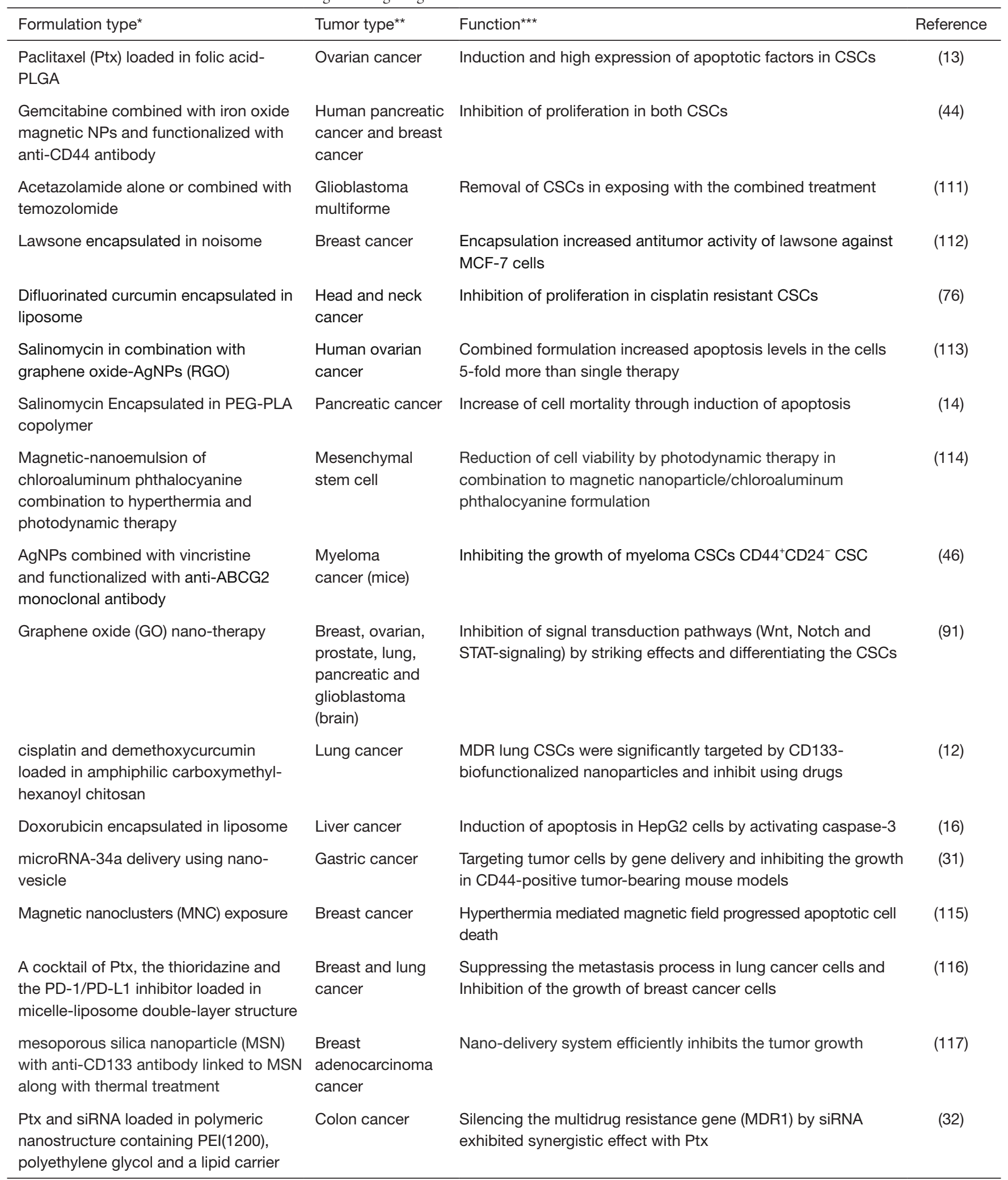

Table 3 (continued) 
Table 3 (continued)

\begin{tabular}{|c|c|c|c|}
\hline Formulation type ${ }^{\star}$ & Tumor type $e^{\star \star}$ & Function $^{\star \star \star}$ & Reference \\
\hline $\begin{array}{l}\text { Combination of nanoquinacrine (NQC) } \\
\text { and GW280264 (ADAM-17 inhibitor } \\
\text { loaded in PLGA }\end{array}$ & $\begin{array}{l}\text { Cervical cancer } \\
\text { (CC) }\end{array}$ & $\begin{array}{l}\text { Combination treatment of the cells with NQC and GW280264 } \\
\text { decreased the proliferation and invasion rates, induced nectin- } 4 \\
\text { expression resulting in metastasis inhibition and the activation } \\
\text { of base excision repair (BER) pathway }\end{array}$ & (118) \\
\hline $\begin{array}{l}\text { Gene delivery (PCPS-STAT3 siRNA and } \\
\text { PCPS-GRP78 siRNA) using polycation- } \\
\text { functionalized Nanoporous silicon } \\
\text { microparticles (PCPS) }\end{array}$ & Breast cancer & $\begin{array}{l}\text { Delivery of PCPS-STAT3 siRNA and PCPS-GRP78 siRNA } \\
\text { reduced STAT3 expression in MDA-MB- } 231 \text { breast cancer cells, } \\
\text { causing remarkable reduction of CSCs in the tumor tissue }\end{array}$ & (34) \\
\hline Ptx encapsulated in liposome & Ovarian cancer & $\begin{array}{l}\text { Intraperitoneal delivery of nanoliposome-Ptx shifted metabolic } \\
\text { program toward the oxidative phosphorylation and resulted in } \\
\text { the suppression of CSCs }\end{array}$ & (119) \\
\hline $\begin{array}{l}\text { Disulfiram in combination with copper, } \\
\text { Cl-isobologram, 5-FU and sorafenib } \\
\text { encapsulated in PLGA }\end{array}$ & Liver cancer & $\begin{array}{l}\text { DS-PLGA combined with copper, significantly inhibited the } \\
\text { liver CSCs. Cl-isobologram exhibited significant synergistic } \\
\text { cytotoxicity against liver cancer when co-delivered with (5-FU)- } \\
\text { DS-PLGA or sorafenib-DS-PLGA }\end{array}$ & (96) \\
\hline $\begin{array}{l}\text { Gamma- } \mathrm{Fe}_{2} \mathrm{O}_{3} @ D M S A \text { in combination } \\
\text { with Ptx and anti-ABCG2 monoclonal } \\
\text { antibody }\end{array}$ & $\begin{array}{l}\text { Multiple myeloma } \\
\text { cancer }\end{array}$ & $\begin{array}{l}\text { Ptx and anti-ABCG2 antibody remarkably inhibited the growth } \\
\text { of CD } 138^{-} \text {CD } 34^{-} \text {cells through elevation of expression of } \\
\text { caspase- } 9 \text {, caspase- } 8 \text { and caspase- } 3 \text {, and down-regulation of } \\
\text { NF- } \mathrm{kB} \text { were observed in CSCs }\end{array}$ & (47) \\
\hline
\end{tabular}

*, the first column demonstrates various types of nanoformulations that obtained from current therapeutic systems; **, second column shows tumor cells or tissues that were treated by nanodrugs; ${ }^{\star \star \star}$, third column summarized function of nano-vehicles. NPs, nanoparticles; CSCs, cancer stem cells; AgNPs, silver nanoparticles; RGO, reduced graphene oxide; Cl, combination index; 5-FU, 5-fluorouracil.

interaction between goserelin with related receptors (126). In a study on treatment of breast cancer spheroids, lipid and polymer nanoparticles containing drugs were used along with ultrasonic waves. Effective treatment for solid tumors requires uniform distribution of anticancer drugs in all parts of the tumor, and the lethal concentration of the drug should be delivered to all resistant cells and CSCs (127). However, penetration of lipid and polymer nanoparticles into hypoxic and necrotized areas of solid tumors, which contain a large number of CSCs, is a major challenge (128).

\section{Perspective of CSCs}

With the assumption of the CSC hypothesis as the major cause of recurrence, heterogeneity and drug resistance of cancer, many researchers concluded that achievement of an effective treatment strategy for complete eradication of tumor masses by focusing on CSCs behavior could be the only way to permanent success in cancer therapy. In fact, such unclear issues related to CSCs refer to aberrant expression of some key genes involved in regulation and integrity of genome and epigenome $(35,129,130)$. In 
some tumors, which genetic changes do not occur at the phenotype surface, genetic differences can be detected among cancer cells subpopulations through genomic profiling studies, which can provide a rational solution for targeting CSCs inside the tumor masses (10). However, it should be noted that despite recent advances in CSCs, due to the highly complicated behavior of CSCs, for targeting this rare population, an in-depth knowledge is needed about details of specific features of CSCs so that a successful therapeutic outcome could be obtained.

\section{Conclusions}

For treating cancer, the disease must be first recognized well, which can be accelerated and facilitated by identification of CSCs. Many researchers believe that instead of concentrating on the treatment of solid tumors, we must focus on the metastasis and complete removal of cancer cells, and in this way, strategies should be utilized to overcome drug resistance and combination therapies. Nanomedicine has a high potential to accelerate the development of effective strategies for treating drug resistance and recurrent cancers. Despite known advances in drug delivery systems and development of nano-based approaches, serious barriers have remained unresolved, including inappropriate absorption and distribution in tumor tissues, obstruction by limbs and reticuloendothelial system macrophages after systemic administration and limited oral bioavailability of these therapies in vivo conditions. It is hoped that the new therapeutic strategies based on nanotechnology could pave the way for eradication of cancer, which is currently a serious concern worldwide.

\section{Acknowledgments}

The authors are appreciated to Lorestan University of Medical Sciences, Razi Herbal Medicines Research Center, researcher staffs for kindly contribution in all preparation of review article.

\section{Footnote}

Conflicts of Interest: The authors have no conflicts of interest to declare.

Ethical Statement: The authors are accountable for all aspects of the work in ensuring that questions related to the accuracy or integrity of any part of the work are appropriately investigated and resolved.

\section{References}

1. Bonnet D, Dick JE. Human acute myeloid leukemia is organized as a hierarchy that originates from a primitive hematopoietic cell. Nat Med 1997;3:730-7.

2. Bomken S, Fišer K, Heidenreich $\mathrm{O}$, et al. Understanding the cancer stem cell. Br J Cancer 2010;103:439.

3. Davis M, Gassner K, Rodriguez-Barrueco R, et al. Stem Cells and Cancer. Stem Cell Genetics for Biomedical Research, Springer, 2018:271-309.

4. Reya T, Morrison SJ, Clarke MF, et al. Stem cells, cancer, and cancer stem cells. Nature 2001;414:105.

5. Pattabiraman DR, Weinberg RA. Tackling the cancer stem cells - what challenges do they pose? Nat Rev Drug Discov 2014;13:497-512.

6. Drewa T, Styczynski J, Szczepanek J. Is the cancer stem cell population "a player" in multi-drug resistance? Acta Pol Pharm 2008;65:493-500.

7. Masamoto Y, Kurokawa M. Targeting chronic myeloid leukemia stem cells: can transcriptional program be a druggable target for cancers? Stem Cell Investig 2018;5:10.

8. Snyder V, Reed-Newman TC, Arnold L, et al. Cancer stem cell metabolism and potential therapeutic targets. Front Oncol 2018;8:203.

9. Wong ALA, Bellot GL, Hirpara JL, et al. Understanding the cancer stem cell phenotype: A step forward in the therapeutic management of cancer. Biochem Pharmacol 2019;162:79-88.

10. Mwenifumbo JC, Marra MA. Cancer genome-sequencing study design. Nat Rev Genet 2013;14:321.

11. de Sousa E Melo F, Vermeulen L. Wnt Signaling in Cancer Stem Cell Biology. Cancers (Basel) 2016. doi: 10.3390/cancers 8070060

12. Huang WT, Larsson M, Lee YC, et al. Dual drugloaded biofunctionalized amphiphilic chitosan nanoparticles: Enhanced synergy between cisplatin and demethoxycurcumin against multidrug-resistant stem-like lung cancer cells. Eur J Pharm Biopharm 2016;109:165-73.

13. Abou-ElNaga A, Mutawa G, El-Sherbiny IM, et al. Novel nano-therapeutic approach actively targets human ovarian cancer stem cells after xenograft into nude mice. Int J Mol Sci 2017. doi: 10.3390/ijms18040813.

14. Daman Z, Montazeri H, Azizi M, et al. Polymeric Micelles of PEG-PLA Copolymer as a Carrier for Salinomycin Against Gemcitabine-Resistant Pancreatic Cancer. Pharm 
Res 2015;32:3756-67.

15. Hu CM, Aryal S, Zhang L. Nanoparticle-assisted combination therapies for effective cancer treatment. Ther Deliv 2010;1:323-34.

16. Inamura K, Komizu Y, Yamakuchi M, et al. Inhibitory effect of hybrid liposomes on the growth of liver cancer stem cells. Biochem Biophys Res Commun 2019;509:268-74.

17. Wang X, Low XC, Hou W, et al. Epirubicin-adsorbed nanodiamonds kill chemoresistant hepatic cancer stem cells. ACS Nano 2014;8:12151-66.

18. Attari F, Zahmatkesh M, Aligholi H, et al. Curcumin as a double-edged sword for stem cells: dose, time and cell type-specific responses to curcumin. Daru 2015;23:33.

19. Mimeault M, Batra SK. Potential applications of curcumin and its novel synthetic analogs and nanotechnology-based formulations in cancer prevention and therapy. Chin Med 2011;6:31.

20. Bradshaw A, Wickremsekera A, Tan ST, et al. Cancer stem cell hierarchy in glioblastoma multiforme. Front Surg 2016;3:21.

21. Glaser T, Han I, Wu L, et al. Targeted nanotechnology in glioblastoma multiforme. Front Pharmacol 2017;8:166.

22. Tran AN, Boyd NH, Walker K, et al. NOS expression and NO function in glioma and implications for patient therapies. Antioxid Redox Signal 2017;26:986-99.

23. Wei X, Chen X, Ying M, et al. Brain tumor-targeted drug delivery strategies. Acta Pharm Sin B 2014;4:193-201.

24. Ha D, Yang N, Nadithe V. Exosomes as therapeutic drug carriers and delivery vehicles across biological membranes: current perspectives and future challenges. Acta Pharm Sin B 2016;6:287-96.

25. Gao H. Progress and perspectives on targeting nanoparticles for brain drug delivery. Acta Pharm Sin B 2016;6:268-86.

26. Ranji P, Salmani Kesejini T, Saeedikhoo S, et al. Targeting cancer stem cell-specific markers and/or associated signaling pathways for overcoming cancer drug resistance. Tumour Biol 2016;37:13059-75.

27. Liu Y, Lu WL, Guo J, et al. A potential target associated with both cancer and cancer stem cells: A combination therapy for eradication of breast cancer using vinorelbine stealthy liposomes plus parthenolide stealthy liposomes. J Control Release 2008;129:18-25.

28. Lu B, Huang X, Mo J, et al. Drug delivery using nanoparticles for cancer stem-like cell targeting. Front Pharmacol 2016;7:84.

29. Pardal R, Clarke MF, Morrison SJ. Applying the principles of stem-cell biology to cancer. Nat Rev Cancer 2003;3:895.

30. Cerna T, Stiborova M, Adam V, et al. Nanocarrier drugs in the treatment of brain tumors. J Cancer Metastasis Treat 2016;2:407-16.

31. Jang E, Kim E, Son HY, et al. Nanovesicle-mediated systemic delivery of microRNA-34a for CD44 overexpressing gastric cancer stem cell therapy. Biomaterials 2016;105:12-24.

32. Liu C, Zhao G, Liu J, et al. Novel biodegradable lipid nano complex for siRNA delivery significantly improving the chemosensitivity of human colon cancer stem cells to paclitaxel. J Control Release 2009;140:277-83.

33. Lopez-Bertoni H, Kozielski KL, Rui Y, et al. Bioreducible Polymeric Nanoparticles Containing Multiplexed Cancer Stem Cell Regulating miRNAs Inhibit Glioblastoma Growth and Prolong Survival. Nano Lett 2018;18:4086-94.

34. Ling H, Fabbri M, Calin GA. MicroRNAs and other noncoding RNAs as targets for anticancer drug development. Nat Rev Drug Discov 2013;12:847.

35. Nawaz M. Extracellular vesicle-mediated transport of non-coding RNAs between stem cells and cancer cells: implications in tumor progression and therapeutic resistance. Stem Cell Investig 2017;4:83.

36. Zhang G, Wang Z, Qian F, et al. Silencing of the ABCC4 gene by RNA interference reverses multidrug resistance in human gastric cancer. Oncol Rep 2015;33:1147-54.

37. Su WP, Cheng FY, Shieh DB, et al. PLGA nanoparticles codeliver paclitaxel and Stat3 siRNA to overcome cellular resistance in lung cancer cells. Int J Nanomedicine 2012;7:4269.

38. Alshehri A, Grabowska A, Stolnik S. Pathways of cellular internalisation of liposomes delivered siRNA and effects on siRNA engagement with target mRNA and silencing in cancer cells. Sci Rep 2018;8:3748.

39. Shen J, Xu R, Mai J, et al. High capacity nanoporous silicon carrier for systemic delivery of gene silencing therapeutics. ACS Nano 2013;7:9867-80.

40. Uchihara T, Ishimoto T, Yonemura A, et al. Therapeutic targets against gastric cancer stem cells interacting with tumor microenvironment. J Cancer Metastasis Treat 2018;4:9.

41. Mostafavi H, Khaksarian M, Joghataei MT, et al. cAMPEpac Pathway Stimulation Modulate Connexin-43 and MicroRNA-21 Expression in Glioma Cells. Basic Clin Neurosci 2015;6:52.

42. Tran AN, Walker K, Harrison DG, et al. Reactive species balance via GTP cyclohydrolase I regulates glioblastoma 
growth and tumor initiating cell maintenance. Neuro Oncol 2018;20:1055-67.

43. Libby CJ, Tran AN, Scott SE, et al. The pro-tumorigenic effects of metabolic alterations in glioblastoma including brain tumor initiating cells. Biochim Biophys Acta Rev Cancer 2018;1869:175-88.

44. Aires A, Ocampo SM, Simões BM, et al. Multifunctionalized iron oxide nanoparticles for selective drug delivery to CD44-positive cancer cells. Nanotechnology 2016;27:065103.

45. Vora P, Seyfrid M, Venugopal C, et al. Bmi1 regulates human glioblastoma stem cells through activation of differential gene networks in CD133+ brain tumor initiating cells. J Neurooncol 2019;143:417-28.

46. Dou J, He X, Liu Y, et al. Targeted therapeutic effect of anti-ABCG2 antibody combined with nano silver and vincristine on mouse myeloma cancer stem cells. J Nanopart Res 2013;15:2127.

47. Yang C, He X, Song L, et al. $\gamma$-Fe2O3 nanoparticles increase therapeutic efficacy of combination with paclitaxel and anti-ABCG2 monoclonal antibody on multiple myeloma cancer stem cells in mouse model. J Biomed Nanotechnol 2014;10:336-44.

48. Klonisch T, Wiechec E, Hombach-Klonisch S, et al. Cancer stem cell markers in common cancers-therapeutic implications. Trends Mol Med 2008;14:450-60.

49. Li B, Li Q, Mo J, et al. Drug-loaded polymeric nanoparticles for cancer stem cell targeting. Front Pharmacol 2017;8:51.

50. Zhang W, Meng Y, Liu N, et al. Insights into chemoresistance of prostate cancer. Int J Biol Sci 2015;11:1160.

51. Jaworska D, Król W, Szliszka E. Prostate Cancer Stem Cells: Research Advances. Int J Mol Sci 2015;16:27433-49.

52. Taylor MD, Poppleton H, Fuller C, et al. Radial glia cells are candidate stem cells of ependymoma. Cancer cell 2005;8:323-35.

53. Wang X, Venugopal C, Manoranjan B, et al. Sonic hedgehog regulates Bmi1 in human medulloblastoma brain tumor-initiating cells. Oncogene 2012;31:187.

54. Xi G, Li YD, Grahovac G, et al. Targeting CD133 improves chemotherapeutic efficacy of recurrent pediatric pilocytic astrocytoma following prolonged chemotherapy. Mol Cancer 2017;16:21.

55. Mostafavi H, Khaksarian M, Joghataei MT, et al. Selective $\beta 2$ adrenergic agonist increases $\mathrm{Cx} 43$ and miR-451 expression via cAMP-Epac. Mol Med Rep 2014;9:2405-10. 56. Aldape K, Zadeh G, Mansouri S, et al. Glioblastoma: pathology, molecular mechanisms and markers. Acta Neuropathol 2015;129:829-48.

57. Kim YJ, Siegler EL, Siriwon N, et al. Therapeutic strategies for targeting cancer stem cells. J Cancer Metastasis Treat 2016;2:233-42.

58. Wang C, Xie J, Guo J, et al. Evaluation of CD44 and CD133 as cancer stem cell markers for colorectal cancer. Oncol Rep 2012;28:1301-8.

59. Taniguchi H, Moriya C, Igarashi H, et al. Cancer stem cells in human gastrointestinal cancer. Cancer Sci 2016;107:1556-62.

60. Lugli A, Iezzi G, Hostettler I, et al. Prognostic impact of the expression of putative cancer stem cell markers CD133, CD166, CD44s, EpCAM, and ALDH1 in colorectal cancer. Br J Cancer 2010;103:382.

61. Liskova A, Kubatka P, Samec M, et al. Dietary Phytochemicals Targeting Cancer Stem Cells. Molecules 2019;24:899.

62. Zhu HB, Zhao MF, Xie F, et al. Clinical significance of leukemia stem/progenitor cell related gene expression in acute leukemia. Zhongguo Shi Yan Xue Ye Xue Za Zhi 2011;19:1150-5.

63. le Viseur C, Hotfilder M, Bomken S, et al. In childhood acute lymphoblastic leukemia, blasts at different stages of immunophenotypic maturation have stem cell properties. Cancer cell 2008;14:47-58.

64. Tuzuner NN, Bennett JM. Classification of the acute leukemias: cytochemical and morphologic considerations. Neoplastic Diseases of the Blood, Springer, 2018:197-236.

65. Qiu S, Jia Y, Xing H, et al. N-Cadherin and Tie2 positive CD34+ CD38- CD123+ leukemic stem cell populations can develop acute myeloid leukemia more effectively in NOD/SCID mice. Leuk Res 2014;38:632-37.

66. Valent P, Sadovnik I, Ráčil Z, et al. DPPIV (CD26) as a novel stem cell marker in $\mathrm{Ph}+$ chronic myeloid leukaemia. Eur J Clin Invest 2014;44:1239-45.

67. Jarocha D, Lukasiewicz E, Majka M. Adventage of mesenchymal stem cells (MSC) expansion directly from purified bone marrow CD105+ and CD271+ cells. Folia Histochem Cytobiol 2008;46:307-14.

68. Yoshida A, Sekine S, Tsuta K, et al. NKX2. 2 is a useful immunohistochemical marker for Ewing sarcoma. Am J Surg Pathol 2012;36:993-9.

69. Zhu J, He J, Liu Y, et al. Identification of glycoprotein markers for pancreatic cancer CD24+CD44+stem-like cells using nano-LC-MS/MS and tissue microarray. J Proteome Res 2012;11:2272-81.

70. Shankar S, Nall D, Tang SN, et al. Resveratrol inhibits 
pancreatic cancer stem cell characteristics in human and KrasG12D transgenic mice by inhibiting pluripotency maintaining factors and epithelial-mesenchymal transition. PloS One 2011;6:e16530.

71. Ning X, Shu J, Du Y, et al. Therapeutic strategies targeting cancer stem cells. Cancer Biol Ther 2013;14:295-303.

72. Yin H, Glass J. The phenotypic radiation resistance of CD44+/CD24- or low breast cancer cells is mediated through the enhanced activation of ATM signaling. PloS One 2011;6:e24080.

73. Ricardo S, Vieira AF, Gerhard R, et al. Breast cancer stem cell markers CD44, CD24 and ALDH1: expression distribution within intrinsic molecular subtype. J Clin Pathol 2011;64:937-46.

74. Mannelli G, Magnelli L, Deganello A, et al. Detection of putative stem cell markers, CD 44/CD 133, in primary and lymph node metastases in head and neck squamous cell carcinomas. A preliminary immunohistochemical and in vitro study. Clin Otolaryngol 2015;40:312-20.

75. Wang SJ, Wong G, de Heer AM, et al. CD44 variant isoforms in head and neck squamous cell carcinoma progression. Laryngoscope 2009;119:1518-30.

76. Basak SK, Zinabadi A, Wu AW, et al. Liposome encapsulated curcumin-difluorinated (CDF) inhibits the growth of cisplatin resistant head and neck cancer stem cells. Oncotarget 2015;6:18504-17.

77. Ohkuma M, Haraguchi N, Ishii H, et al. Absence of CD71 transferrin receptor characterizes human gastric adenosquamous carcinoma stem cells. Ann Surg Oncol 2012;19:1357-64.

78. Lee H, Yang SH, Heo D, et al. Molecular imaging of CD44-overexpressing gastric cancer in mice using T2 MR imaging. J Nanosci Nanotechnol 2016;16:196-202.

79. Crowe DL, Parsa B, Sinha U. Relationships between stem cells and cancer stem cells. Histol Histopathol 2004;19:505-09.

80. Piao LS, Hur W, Kim TK, et al. CD133+ liver cancer stem cells modulate radioresistance in human hepatocellular carcinoma. Cancer Lett 2012;315:129-37.

81. Wang L, Su W, Liu Z, et al. CD44 antibody-targeted liposomal nanoparticles for molecular imaging and therapy of hepatocellular carcinoma. Biomaterials 2012;33:5107-14.

82. Lee WC. Cell-mediated immunotherapy for hepatocellular carcinoma. J Cancer Metastasis Treat 2017;3:244-9.

83. Tjhay F, Motohara T, Tayama S, et al. CD 44 variant 6 is correlated with peritoneal dissemination and poor prognosis in patients with advanced epithelial ovarian cancer. Cancer Sci 2015;106:1421-28.

84. Chefetz I, Alvero A, Holmberg J, et al. TLR2 enhances ovarian cancer stem cell self-renewal and promotes tumor repair and recurrence. Cell Cycle 2013;12:511-21.

85. Prabavathy D, Swarnalatha Y, Ramadoss N. Lung cancer stem cells-origin, characteristics and therapy. Stem Cell Investig 2018;5:6.

86. Yan X, Luo H, Zhou X, et al. Identification of CD90 as a marker for lung cancer stem cells in A549 and H446 cell lines. Oncol Rep 2013;30:2733-40.

87. Karkhane M, Marzban A, Rafiei A, et al. Cancer Stem Cells: Cell Heterogeneity in Cancer and Nanotechnology Approaches for Their Treatment. J Mazandaran Univ Med Sci 2016;25:361-75.

88. de Almeida BP, Vieira AF, Paredes J, et al. Pan-cancer association of a centrosome amplification gene expression signature with genomic alterations and clinical outcome. PLoS Comput Biol 2019;15:e1006832.

89. Kim W'T, Ryu CJ. Cancer stem cell surface markers on normal stem cells. BMB Rep 2017;50:285.

90. von Maltzahn J, Bentzinger CF, Rudnicki MA. Wnt7aFzd7 signalling directly activates the Akt/mTOR anabolic growth pathway in skeletal muscle. Nat Cell Biol 2011;14:186-91.

91. Fiorillo M, Verre AF, Iliut M, et al. Graphene oxide selectively targets cancer stem cells, across multiple tumor types: Implications for non-toxic cancer treatment, via "differentiation-based nano-therapy". Oncotarget 2015;6:3553-62.

92. Pang Y, Liu J, Li X, et al. Nano Let.7b sensitization of eliminating esophageal cancer stem.like cells is dependent on blockade of $\mathrm{Wnt}$ activation of symmetric division. Int J Oncol 2017;51:1077-88.

93. Lai KKY, Kweon SM, Chi F, et al. Stearoyl-CoA Desaturase Promotes Liver Fibrosis and Tumor Development in Mice via a Wnt Positive-Signaling Loop by Stabilization of Low-Density LipoproteinReceptor-Related Proteins 5 and 6. Gastroenterology 2017;152:1477-91.

94. Saeg F, Anbalagan M. Breast cancer stem cells and the challenges of eradication: a review of novel therapies. Stem Cell Investig 2018;5:39.

95. Jaiswal S, Traver D, Miyamoto T, et al. Expression of BCR/ABL and BCL-2 in myeloid progenitors leads to myeloid leukemias. PNAS 2003;100:10002-7.

96. Wang Z, Tan J, McConville C, et al. Poly lactic-co-glycolic acid controlled delivery of disulfiram to target liver cancer stem-like cells. Nanomedicine 2017;13:641-57. 
97. Mao J, Fan S, Ma W, et al. Roles of Wnt/ $\beta$-catenin signaling in the gastric cancer stem cells proliferation and salinomycin treatment. Cell Death Dis 2014;5:e1039.

98. Abdullah LN, Chow EK. Mechanisms of chemoresistance in cancer stem cells. Clin Transl Med 2013;2:3.

99. Mondal S, Bhattacharya K, Mandal C. Nutritional stress reprograms dedifferention in glioblastoma multiforme driven by PTEN/Wnt/Hedgehog axis: a stochastic model of cancer stem cells. Cell Death discov 2018;4:110.

100. Takebe N, Harris PJ, Warren RQ, et al. Targeting cancer stem cells by inhibiting Wnt, Notch, and Hedgehog pathways. Nat Rev Clin Oncol 2011;8:97.

101. Morgenroth A, Vogg ATJ, Ermert K, et al. Hedgehog signaling sensitizes Glioma stem cells to endogenous nanoirradiation. Oncotarget 2014;5:5483-93.

102. Nayak A, Satapathy SR, Das D, et al. Nanoquinacrine induced apoptosis in cervical cancer stem cells through the inhibition of hedgehog-GLI1 cascade: Role of GLI-1. Sci Rep 2016;6:20600.

103. Karamboulas C, Ailles L. Developmental signaling pathways in cancer stem cells of solid tumors. Biochim Biophys Acta 2013;1830:2481-95.

104. Venkatesh V, Nataraj R, Thangaraj GS, et al. Targeting Notch signalling pathway of cancer stem cells. Stem Cell Investig 2018;5:5.

105.Harrison H, Farnie G, Howell SJ, et al. Regulation of breast cancer stem cell activity by signaling through the Notch4 receptor. Cancer Res 2010;70:709-18.

106. Prasad S, Ravindran J, Aggarwal BB. NF- $\kappa$ B and cancer: how intimate is this relationship. Mol Cell Biochem 2010;336:25-37.

107.Demain AL, Vaishnav P. Natural products for cancer chemotherapy. Microb Biotechnol 2011;4:687-99.

108. Alipour M, Bigdeli M, Rasoulian B, et al. Reviews of Natural Products and Herbal Medicines in Treatment of Cancer. Int J Adv Biotechnol Res 2017;8:2127-39.

109. Kreitman RJ. Recombinant toxins for the treatment of cancer. Curr Opin Mol Ther 2003;5:44-51.

110. Marianecci C, Carafa M. Smart Nanovesicles for Drug Targeting and Delivery. Multidisciplinary Digital Publishing Institute, 2019.

111. Amiri A, Le PU, Moquin A, et al. Inhibition of carbonic anhydrase IX in glioblastoma multiforme. Eur J Pharm Biopharm 2016;109:81-92.

112. Barani M, Mirzaei M, Torkzadeh-Mahani M, et al. Lawsone-loaded Niosome and its antitumor activity in MCF-7 breast Cancer cell line: a Nano-herbal treatment for Cancer. Daru 2018;26:11-7.
113. Choi YJ, Gurunathan S, Kim JH. Graphene oxide-silver nanocomposite enhances cytotoxic and apoptotic potential of salinomycin in human ovarian cancer stem cells

(OvCSCs): A novel approach for cancer therapy. Int J Mol Sci 2018. doi: 10.3390/ijms19030710.

114. De Paula LB, Primo FL, Pinto MR, et al. Combination of hyperthermia and photodynamic therapy on mesenchymal stem cell line treated with chloroaluminum phthalocyanine magnetic-nanoemulsion. J Magnet Magnetic Mater 2015;380:372-6.

115.Kwon YS, Sim K, Seo T, et al. Optimization of magnetic hyperthermia effect for breast cancer stem cell therapy. RSC Adv 2016;6:107298-304.

116.Lang T, Liu Y, Zheng Z, et al. Cocktail Strategy Based on Spatio-Temporally Controlled Nano Device Improves Therapy of Breast Cancer. Adv Mater 2019;31:e1806202. Erratum in: Adv Mater 2019;31:e1903844.

117.Li H, Yan W, Suo X, et al. Nucleus-targeted nano delivery system eradicates cancer stem cells by combined thermotherapy and hypoxia-activated chemotherapy. Biomaterials 2019;200:1-14.

118. Nayak A, Das S, Nayak D, et al. Nanoquinacrine sensitizes 5-FU-resistant cervical cancer stem-like cells by downregulating Nectin-4 via ADAM-17 mediated NOTCH deregulation. Cell Oncol (Dordr) 2019;42:157-71.

119. Shen YA, Li WH, Chen PH, et al. Intraperitoneal delivery of a novel liposome-encapsulated paclitaxel redirects metabolic reprogramming and effectively inhibits cancer stem cells in Taxol®-resistant ovarian cancer. Am J Transl Res 2015;7:841-55.

120. Tran TA, Krishnamoorthy K, Cho SK, et al. Inhibitory effect of zinc sulfide nanoparticles towards breast cancer stem cell migration and invasion. J Biomed Nanotechnol 2016;12:329-36.

121. Upreti M, Jyoti A, Sethi P. Tumor microenvironment and nanotherapeutics. Transl Cancer Res 2013;2:309.

122. Martin AR, Ronco C, Demange L, et al. Hypoxia inducible factor down-regulation, cancer and cancer stem cells (CSCs): ongoing success stories. MedChemComm 2016;8:21-52.

123. Naveen SV, Kalaivani K. Cancer stem cells and evolving novel therapies: a paradigm shift. Stem Cell Investig 2018;5:4.

124. Glazer ES, Zhu C, Massey KL, et al. Noninvasive radiofrequency field destruction of pancreatic adenocarcinoma xenografts treated with targeted gold nanoparticles. Clin Cancer Res 2010;16:5712-21.

125. Chithrani DB, Jelveh S, Jalali F, et al. Gold nanoparticles 
as radiation sensitizers in cancer therapy. Radiat Res 2010;173:719-28.

126. Wolfe T, Chatterjee D, Lee J, et al. Targeted gold nanoparticles enhance sensitization of prostate tumors to megavoltage radiation therapy in vivo. Nanomedicine 2015;11:1277-83. Erratum in: Nanomedicine 2016;12:851-2.

127.Zhao YZ, Du LN, Lu CT, et al. Potential and problems in ultrasound-responsive drug delivery systems. Int J Nanomedicine 2013;8:1621.

doi: $10.21037 /$ sci.2019.10.07

Cite this article as: Basati G, Khaksarian M, Abbaszadeh S, Lashgarian HE, Marzban A. Cancer stem cells and nanotechnological approaches for eradication. Stem Cell Investig 2019;6:38.
128. Harrison L, Blackwell K. Hypoxia and anemia: factors in decreased sensitivity to radiation therapy and chemotherapy? Oncologist 2004;9 Suppl 5:31-40.

129.Farahmand L, Darvishi B, Salehi M, et al. Functionalised nanomaterials for eradication of CSCs, a promising approach for overcoming tumour heterogeneity. J Drug Target 2018;26:649-57.

130. Hu J, Locasale JW, Bielas JH, et al. Heterogeneity of tumor-induced gene expression changes in the human metabolic network. Nat Biotechnol 2013;31:522. 